\title{
Hearing Protection: Selection Factors and Risks of Excessive Attenua- tion
}

\author{
M. L. Matos \\ LNEG/FEUP, Portugal \\ P. Santos \\ A.Ramalhão, Porto, Portugal \\ F. Barbosa \\ Cinfu, Porto, Portugal
}

ABSTRACT: Currently, noise exposure in the occupational setting continues to be a problem in industrialized countries, not only because this is the most common occupational disease in these countries, but also because it is transversal to all activity sectors, including leisure activities. Exposure to high noise levels can affect the hearing system. For this reason, the legislation requires that the employer implements a set of measures to protect the exposed worker, and as last solution the use of individual hearing protection. However, what occurs in practice and in the majority of cases is the adoption of the use of hearing protection, at the expense of collective protective measures. Nevertheless, not always their selection is made of the most efficient manner. Excessive attenuation of the protectors, as well as the existence of sectors where impulsive noise is produced, are currently the main concerns of safety technicians.

\section{INTRODUCTION}

Currently, noise exposure in the occupational setting continues to be a problem in industrialized countries, not only because this is the most common occupational disease in these countries, but also because it is transversal to all activity sectors, Abelenda (2006) including leisure activities. The perception of workers to hearing problems increased slightly. According to the results from the European survey, Eurogip, (2004), 7\% of European workers consider that work affects their health in terms of hearing disorders. Workers who say they are subject to a higher level of noise exposure are also those who report more hearing problems.

The noise in the workplace is a global problem that affects a wide range of industrial sectors. Excessive exposure to noise can cause hearing problems, and they may arise from exposure to either a brief impulsive noise (over 140 decibels (dB (C)) or exposure to high intensity noise (more than 85 decibels (dB (A )) for several hours each day, during a long period of time (a few years) Within the EU-27, it is estimated that there are 60 million workers - $30 \%$ of the workforce - exposed to noise, OSHA, (2009). Due to this reason, we list some important facts about the disturbances of hearing caused by noise in the workplace:

- The disorders are often accompanied by tinnitus, or buzz in the ears.
- The cost of hearing disorders caused by noise correspond to approximately $10 \%$ of the total cost of compensation for occupational diseases.

- The acknowledged incidence of hearing disorders differs, depending on the country and of the recognition policies. In 2005, the difference between the Member States was quite evident: $5.9 \%$ of EU-15 workers complained about hearing problems, against $13.5 \%$ in the 10 new Member States and $9.7 \%$ in Bulgaria and Romania.

- The largest numbers of cases are registered in the age groups of 40 to 54 years and of 55 to 60 years, OSHA, (2009).

Exposure to high noise levels can affect the hearing system. For this reason, the legislation requires that the employer implements a set of measures to protect the exposed worker. The purpose of these measures, both of technical and organizational nature, is to inform workers, medical surveillance and, as a last resort, the use of individual hearing protection, among other aspects. However, what occurs in practice and in the majority of cases is the adoption of the use of hearing protection, at the expense of collective protective measures, due to the direct economical cost that some of these measures entail. As a consequence, the use of hearing protection equipment has increased. However, not always it's selection is made of the most efficient manner done as efficiently. One of the most frequently-cited objections by workers is that they feel they are unable to hear speech and warning signals when they are wearing 
hearing protection equipment, Suter (1992), Wilkins \& Martin, (1987). The excessive attenuation of hearing protectors, as well as the existence of sectors in which labor activity noises occur with specific characteristics of the impulsive type, are currently the main concerns of safety technicians.

\section{RISKS AND SCENARIOS}

\subsection{Risks and factors for selection of individual hearing protection}

Noise is not only a harm to the health, but being responsible for lowering the workers' attention, reduces the quality of the work environment. Particularly, noise makes difficult the communication between workers and the perception of sounds used by machines and working places, which can have serious consequences on workers safety that can lead to accidents. A personal protective equipment is a device designed to be used by a person; due to its characteristics in terms of acoustic attenuation, it reduces the harmful effects caused by noise on hearing.

The choice must be careful in order to assure that the hearing protectors supplied to the user don't cause an excessive attenuation. This situation can cause difficulties in communication, hearing and warning sounds differentiation, such as machinery and sound alarms for evacuation, in case of emergency. In this case, many workers state that they feel uncomfortable, that they do not hear or understand coworkers, do not hear the equipment noises and the warning sounds and that they feel isolated from the surrounding environment. As a result, they end up not using the hearing protectors thus endangering their hearing health.

Some studies on noise protection, Niquette, (2006) show that most of the protectors that are used cause an excessive attenuation at certain frequencies. The selection of hearing protectors involves preliminary analysis of several factors related to the noise in question (see Figure 1 diagram).

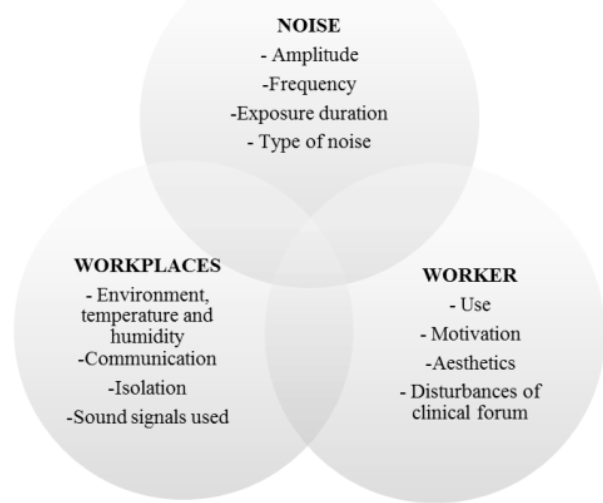

Figure 1 - Diagram of the factors to be considered in selecting hearing protectors. INRS (2009).
Probably the ideal protector does not exist. Therefore, on one hand, hearing protectors should be chosen based on their capability to attenuate the noise, in order to protect the worker, without restricting the hearing of warning sounds of working places and without making difficult the communication between colleagues. On the other hand, the use of hearing protectors, during the whole exposure period, should be ensured. Due to these two reasons, the appropriate protector is the one that enables a reasonable a safety level and, at the same time, it is compatible with the comfort conditions.

The NP EN 458 contains recommendations regarding selection of hearing protectors, its use and usage care. According to this standard, a hearing protector must reduce noise to levels, below the action levels. This means that is the exposure level should be less than or equal to the action level set for each particular country, which requires the use of hearing protectors. According to the Portuguese Law Decree 182 of the year 2006, Decreto, (2006), there are two action levels, the lower: $80 \mathrm{~dB}$ (A) and the higher: $85 \mathrm{~dB}(\mathrm{~A})$. Subparagraph b) of the $7^{\text {th }}$ Article, establishes that the higher action level requires the mandatory use of hearing protectors, and the employer must assure the use of individual hearing protection. Table 1 shows an example of the evaluation of the level of attenuation provided by of a hearing protector, at a specific noise situation.

Desirable attenuation in the ear

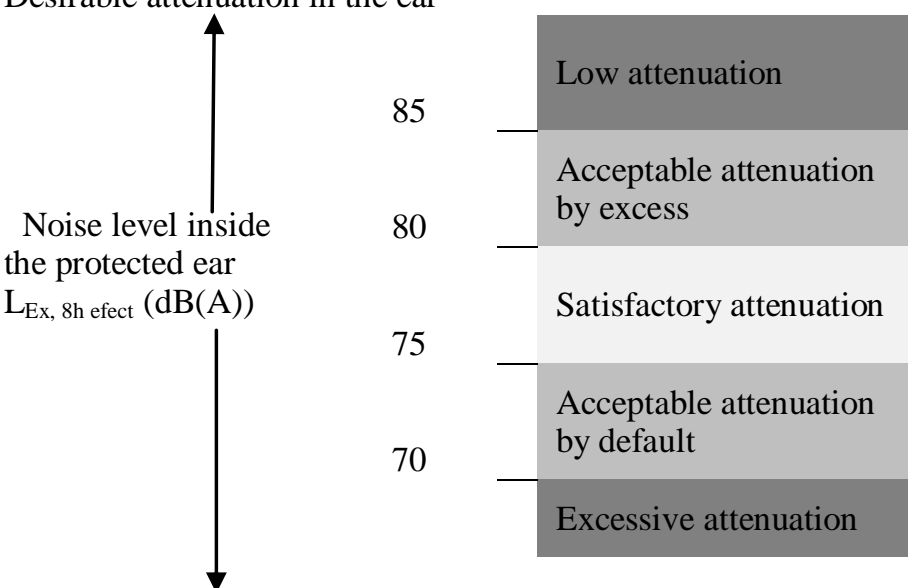

Figure 2 - Evaluation of the hearing protector attenuation. Adapted from IPQ, (2006).

\subsection{Noise exposure scenarios}

Many or almost all industrial activities are responsible for workers exposure to very high noise levels, although there is concern in keeping workers protected. Some activities require more demanding protection measures due to their specific needs. Thus, Neves \& Soalheiro, (2007), a study carried out in the School for the Improvement of Army Officers, tried to identify noise exposure and to evaluate if the hearing protection used by these workers was adequate for the exposure to impact noise during activities of Basic Shooting Instruction conducted in the 
Brazilian Army. In view of the conducted analysis, the author, Neves \& Soalheiro, (2007), concluded that those workers were exposed to a minimum sound pressure level of $147.3 \mathrm{~dB}$ during shooting activities, and that this value could reach $171 \mathrm{~dB}$. Hearing protection for this activity should provide not only noise attenuation, but also the possibility of understanding the orders and guidelines given during it. According to Berger, (2003), there are four paths ways in which sound can reach the ear, even when it is protected by an hearing protector: air gaps - , if there is no adequate adaptation of the hearing protector to the ear, this can lead to the occurrence of a attenuation reduction of about 5 to $15 \mathrm{~dB}$, over a wide frequency band; protector vibration - when insert into ear protectors are used, vibration may occur, which is proportional to the hearing canal flexibility and can reduce the attenuation at low frequencies; transmission by the material - it is related to the mass, stiffness and sealing materials and transmission through bone and tissues. The protector usage period should also be considered when evaluating its attenuation effectiveness, since the intermittent use of that this device will cause a significant reduction of its efficiency, Berger, (2003).

\section{ANALYSIS AND SOLUTIONS}

\subsection{Analysis}

Given the mentioned selection factors, in particular when excessive attenuation is detected, it is necessary to select a protector with uniform attenuation which enables to provide a similar attenuation over a wide frequency range, thus supporting effective communications. When it is necessary that determined informative sounds are heard in the work environment or that they are recognized, such as the acknowledgment signals or verbal messages is advisable to use hearing protectors with a uniform attenuation feature across the frequency range. Risk assessment and characteristics of the job are crucial in the selection of suitable protector.Quantitative parameters such as noise level and spectral analysis as well as qualitative parameters such as environmental conditions must be analyzed. To aid the risk assessment, as an example we present in table 1, a checklist based in the original presented in INRS (2009). We suggested additional information, like as: clinical disorders, training and information of workers, contemplate de ototoxic agents and de accidents/incidents investigation. This checklist may be more or less comprehensive and detailed as the situation to apply. This working tool may also serve to promote further discussion among stakeholders: workers, employers, suppliers and manufacturers.For the choice of individual hearing protection, entities may also be able to appeal to the medicine at work to find the solution most adequate for workers with clinical problems, such as irritations, allergies and hearing aids.

Table 1 - List (exemplary) for risk assessment of exposure to noise and selection of hearing protectors. Adapted from INRS,(2009)

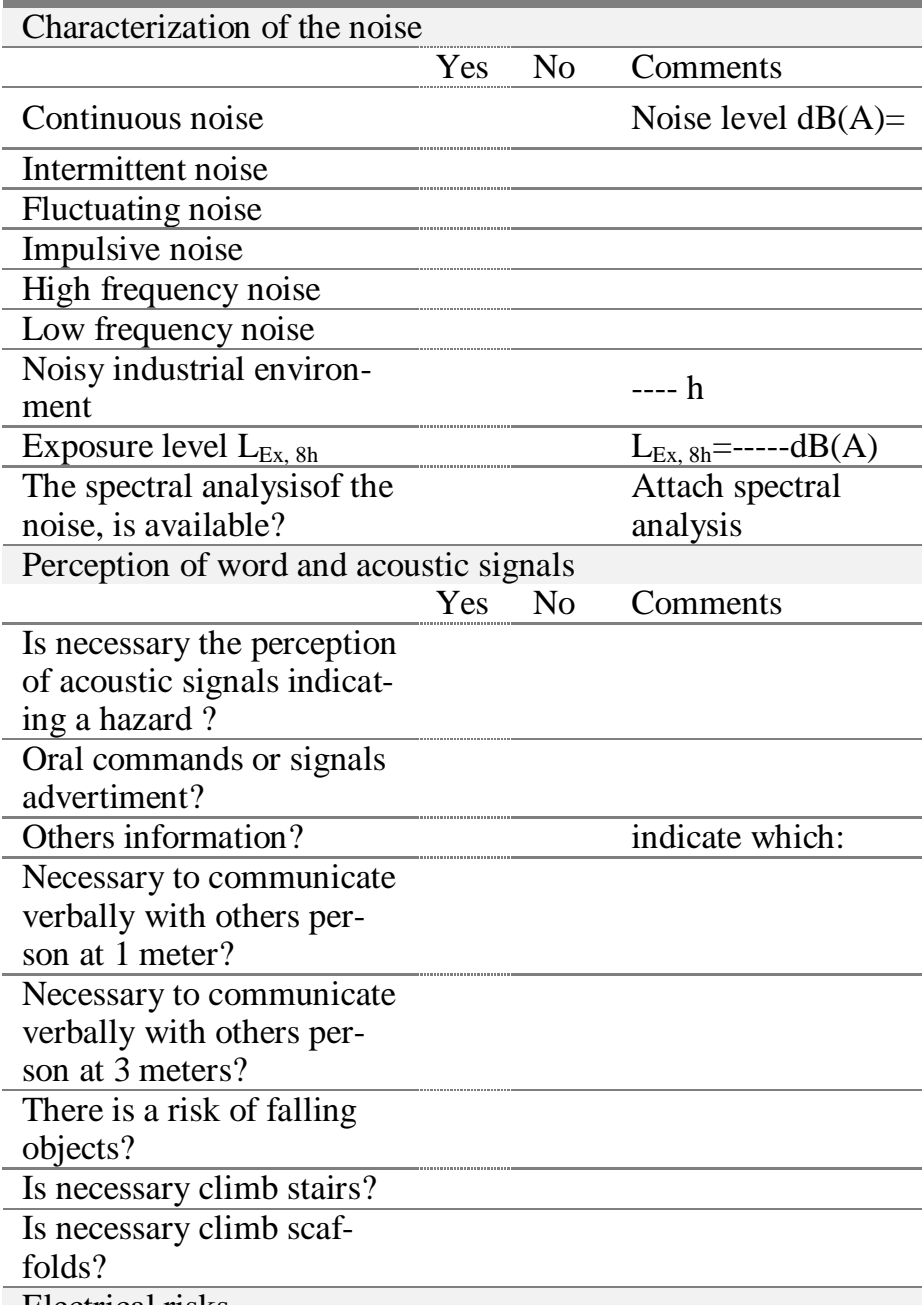

Electrical risks

\begin{tabular}{llll} 
& Yes & No & Comments \\
\hline Electrical contacts? & & & Tension (Volts) $=$ \\
\hline Electrostatic discharge? & & & \\
\hline Environmental conditions & Yes No $\quad$ Comments
\end{tabular}

Cold

Heat

Humidity

Rain or snow

Chemical risk

Yes No Comments

Dust

Liquid and droplets

Gases

Fumes

Aerosols

Ototoxic agents

Safety cards are available?

Hearing protection and PPE

Yes No Comments

There removal and replacement of hearing protection is frequent?

Simultaneous use of PPE? Helmet 
Glasses

Masks

\begin{tabular}{|c|c|c|c|}
\hline \multicolumn{4}{|l|}{ Clinical Disorders } \\
\hline & Yes & No & Comments \\
\hline $\begin{array}{l}\text { There are workers on the } \\
\text { job with clinical disor- } \\
\text { ders? }\end{array}$ & & & $\begin{array}{l}\text { Consulting the oc- } \\
\text { cupational doctor }\end{array}$ \\
\hline Training and information & & & \\
\hline
\end{tabular}

About the exposure risks?

About the prevention

measures?

How to correctly use the

hearing protectors?

Accidents/incidents Investigation

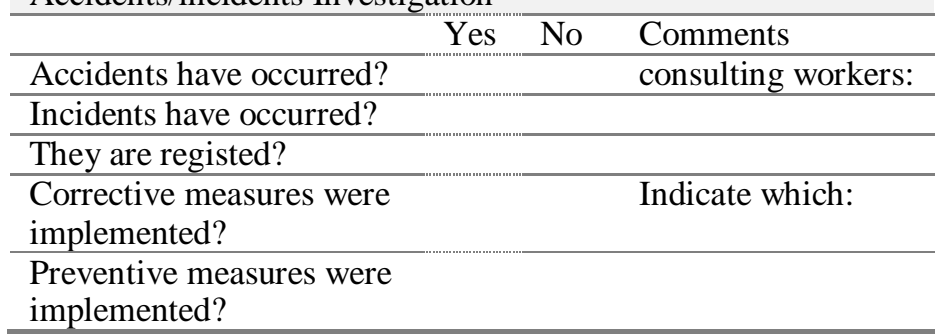

\subsection{Solutions}

There are various solutions available in the market that solve problems of excessive attenuation on worker protection, that isolate the verbal communication and warning sounds of the environment that surrounds it. The passive hearing protectors are the type of hearing protector more known and used or alternatively the not passive hearing protectors equipped with electronic components that open new horizons in hearing protection. Electronic protectors use electronic microphone and speakers with built-in functions of dangerous noise attenuation with multiple levels of volume regulated by button. May allow amplifying lower ambient noises, in stereo, so that the user be aware of the direction of its source and reduce unwanted loud noises.

There are also with Bluetooth communication function, with microphone fitted with noise filtering, to allow clear communication with other workers even in very noisy environments. Protectors with radio may allow communicating with other radios or mobile phones or connect to CD or MP3 or FM radio for listening to music or news while meeting the priority input external signal communication for security reasons, as exemplified in Figure 3.

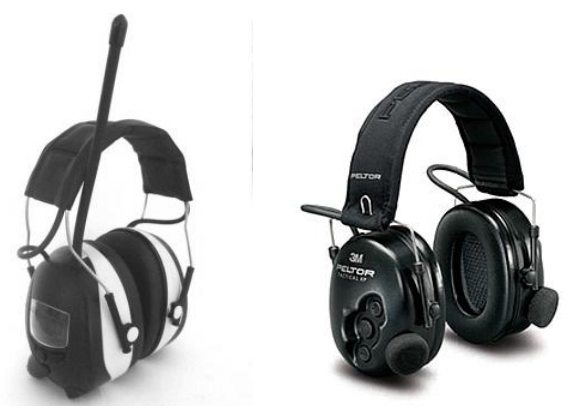

Figure 3-ElectronicHearingProtectorswithMP3orCD players and radio.
Electronic protectors may have electronic voice function to confirm the electronic volume and filtering adjustments without removing them, and active volume function to avoid unpleasant abrupt sound cuts when occur impulsive noise. The protection function with level dependence improves audibility of vital communications and emergency sounds in intermittent noise environments.

The latest hearing protectors are comfortable using for example liquid pads and ergonomic designs, and can even lead you to forget that you're using it, as a good protector should do.

Within the passive hearing protectors also already exist models with manual listening function, that pressing a button reduces attenuation and allow you to hear conversations and communicate verbally while maintaining some protection. The hearing protectors can also be used as a visual security, existing in bright colors for high visibility.

Given the range of solutions offered, when monitoring the use of hearing protectors by the safety technician and in situations where the employee has been provided a device that allows connection to CD players, MP3 or FM radio, should also be controlled its misuse. Although this option can work as a motivating factor for the use of hearing protectors, it can become a risk factor.

\section{CONCLUSIONS}

The hearing protector may not be the ideal, but currently, the market already offers several solutions to situations of excessive attenuation and exposure to impulsive noise. However, concern about these aspects, which are felt and expressed by workers, cannot be analyzed as an isolated event, but having to be a comprehensive analysis of various groups of factors that influence the selection of hearing protectors. Thus, using the risk assessment and analysis of global interaction of factors, we are on the way to find the ideal protector.

\section{REFERENCES}

Abelenda, C. S. 2006. Avaliação do Conforto de Protetores individuais auditivos. U. Minho, Ed. Guimarães.

Berger, E. H. 2003. Patologia do Trabalho.

ESWC. 2005. Inquérito Europeu sobre as Condições de Trabalho.

Decreto, L. 2006. Prescrições mínimas de segurança e de saúde em matéria de exposição dos trabalhadores aos riscos devidos aos agentes físicos ruído.

Eurogip Agosto de 2004. Costs and funding of occupational diseases in Europe. Obtido em 9 de 
11 de 2012, de Eurogip: http://www.eurogip.fr/pdf/Eurogip-08E-cost.pdf INRS 2009. Les équipements de protection individuelle de l' ouie. Choix et utilization.

IPQ 2006. NP EN 458. Protetores auditivos. Recomendações relativas à seleção, à utilização, aos cuidados na utilização e à manutenção. Documento guia.

Neves, E. B., \& Soalheiro, M. 2007. A proteção auditiva utilizada pelos militares do Exercito brasileiro: há efectividade? Revista Temas Livres, pp. 889-898.

Niquette, P. 2006. Hearing protection for musicians. The Hearing Review.

OSHA 2009. Novos Riscos Emergentes para a Segurança e Saúde no trabalho. Luxemburgo: Serviço das Publicações Oficiais das Comunidades Europeias.

OSHA Janeiro de 2009. Perspectivas 1 - Novos riscos emergentes para segurança e saúde no trabalho. Agência Europeia para a Segurança e Saúde no Trabalho.

Suter, A.H. 1992. The effects of Hearing protectors on the perception of speech and warning signals. ASHA Monografs, 28.

Wilkins, P., \& Martin, A. M. 1987. Hearing protection and warning sounds in industry: a review. Applied Acoustics, 24, pp. 267-293. 